\title{
LA BODA ENTRE FERNANDO III EL SANTO Y BEATRIZ DE SUABIA: MOTIVOS Y PERSPECTIVAS DE UNA ALIANZA MATRIMONIAL ENTRE LA CORONA DE CASTILLA Y LOS STAUFER
}

\author{
Daniel Colmenero López
}

\begin{abstract}
RESUMEN:
Las relaciones medievales entre el reino de Castilla y los Staufer se iniciaron en los siglos XII y XIII mediante tres alianzas matrimoniales. No obstante, sólo la última de estas bodas, celebrada entre Fernando III el Santo y Beatriz de Suabia en el año 1219 realmente intensificó las relaciones entre las dos coronas de la que además surgió una amistad entre el rey castellano y el emperador Federico II. En el estudio se analizarán los motivos que llevaron a la alianza matrimonial del año 1219. Contrastando los motivos derivados de nuestras fuentes que se redactaron en los años 30 del siglo XIII con el contexto político en el momento de la boda se hace patente que en realidad fueron motivos de índole táctica, ya sea de parte de la corona de Castilla o de Alemania. Además se puede deducir que las fuentes intentan aportar legitimación al rey posteriormente.
\end{abstract}

Palabras clave: Castilla, Staufer, alianzas matrimoniales, Fernando III, Beatriz de Suabia, Federico II.

\begin{abstract}
:
The medieval relations between the kingdom of Castile and the House of Hohenstaufen were established by three matrimonial alliances in the 13th century. Nevertheless, only the third marriage between Ferdinand III of Castile and Beatrix of Swabia in 1219 intensified the relations between the two crowns. Furthermore, it gave rise to amity between the King of Castile and the emperor Frederick II. The following study analyzes the motives that had lead to the marriage of 1219 . Contrasting the motives as presented by sources written in the 30 s of the 13th century with the political context in which the marriage took place exposes that both the Castilian and the German crown pursued this marriage for tactical reasons. It is also possible to show that these sources try to legitimize the king in retrospect.
\end{abstract}

Fecha de recepción: 20 de octubre de 2009. Fecha de aceptación: 8 de enero de 2010

1 Rheinische Friedrich-Wilhelms-Universität Bonn, Rep. Fed. Alemania. E-Mail: daniel@colmenerolopez.de. 
Keywords: Castile, House of Hohenstaufen, matrimonial alliances, Ferdinand III of Castile, Beatrix of Swabia, Frederick II.

La historia de la relaciones medievales entre el Imperio y el reino de Castilla ha sido determinada por tres bodas que tuvieron lugar en los siglos 12 y $13 .{ }^{2}$ El primer matrimonio se celebró en el año 1158 entre Alfonso VII y Richeza de Polonia. ${ }^{3}$ Richeza era prima hermana del emperador Federico I Barbarroja, de la familia de los Staufer. ${ }^{4}$ El segundo matrimonio se planificó en el año 1188 entre Berenguela de Castilla y Conrado de Rothenburgo, quinto hijo del emperador Federico I Barbarroja, pero no llegó a consumarse. ${ }^{5}$ De estos dos primeros matrimonios del siglo 12, ninguno tuvo efecto duradero en las relaciones entre el Imperio y el reino de Castilla. Se realizaron en situaciones especificas con miras a una mejora a corto plazo de la situación política de poder pero no llevaron a unas relaciones profundas entre los soberanos de los dos reinos. ${ }^{6}$

El tercer matrimonio tuvo lugar en el año 1219 entre Fernando III de Castilla y Beatriz de Suabia y llegó a abrir las puertas a los miembros familiares de la corona hacia nuevas perspectivas europeas. Sólo una generación después, Alfonso X el sabio, que nació como hijo primogénito del matrimonio entre Fernando y Beatriz, se consideraba heredero legítimo de los Staufer. Por consiguiente, en el año 1246 reivindicó su herencia maternal en Suabia ${ }^{7}$ y llegó a ser elegido rey de Romanos en el año $1257 .{ }^{8}$ De esta manera se le abrió

2 MEYER, B. B., "Dynastische Verbindungen zwischen Kastilien und dem Reich zur Zeit der Staufer", en: España y el "Sacro Imperio." Procesos de cambios, influencias y acciones recíprocas en la época de la “europeización” (siglos XI-XIII), ed. J. VALDEÓN/K. HERBERS/K. RUDOLF (Historia y Sociedad, vol. 97), Valladolid 2002, pp. 63-85.

3 Véase MEYER, B. B., Kastilien, die Staufer und das Imperium. Ein Jahrhundert politischer Kontakte im Zeichen des Kaisertums (Historische Studien, vol. 466), Husum 2002, pp. 29-48.

4 La abuela de Richeza y Federico I Barbaroja era Inés de Waiblingen, hija del emperador Enrique IV y Bertha de Saboya. Europäische Stammtafeln. Neue Folge, ed. D. SCHWENNICKE, vol. 1, 1: Die fränkischen Könige und Kaiser, Stammesherzoge, Kurfürsten, Markgrafen und Herzoge des Heiligen Römischen Reiches Deutscher Nation, Fráncfort del Meno 1998, tabla 12. Véase además AVERKORN, R., Kastilien als europäische Großmacht im Spätmittelalter. Grundprobleme der auswärtigen Beziehungen der kastilischen Könige vom 13. bis zum 15. Jahrhundert, en: Auswärtige Politik und internationale Beziehungen im Mittelalter (13. bis 16. Jahrhundert), ed. D. BERG/M. KINTZINGER/P. MONNET (Europa in der Geschichte. Schriften zur Entwicklung des modernen Europa, vol. 6), Bochum 2002, pp. 315-346, p. 316.

5 Véase MEYER, Kastilien-Staufer, pp. 49-66.

6 IBID., pp. 37-48, 63-71.

7 Alfonso estaba en contacto con el papa Inocencio IV para poder deducir los derechos de su herencia maternal en Suabia. En una carta del 3 de mayo de 1246 el papa le consideraba como heredero legítimo de su madre: "Nobili viro Alfonso primogenito carissimi in Christo filii nostri illustris regis Castelle et Legionensis. (...). Cum itaque tua, sicut asseris, ad hoc dirigatur intentio, ut ius, quod clare memorie Beatrix regina Castelle et Legionis, mater tua, in ducatu Suevie dicitur habuisse, ad te perveniat, ipsius heredem, de benignitate sedis apostolice te plenam volumus habere fiduciam, quod si dictum ius assumpseris legitime prosequendum vel eiusdem acquisitio tibi iusto modo provenerit, iamdicta sedes, quantum cum Deo et honestate posse dabitur, tibi super hoc benigni favoris auxilium largietur. "Epistolae saeculi XIII e regestis Pontificum Romanorum selectae per G. H. PERTZ, ed. K. RODENBERG (MGH epp. saec. XIII), Berlín 1887, vol. 2, nr. 180, pp. $136 f$.

8 En cuanto a la elección de Alfonso como rey de Romanos, véase BALLESTEROS-BERETTA, A., Alfonso X el Sabio, Barcelona 1963, pp. 175-212, GONZÁLEZ JIMÉNEZ, M., Alfonso X el Sabio, Barcelona 2004, pp. 116-120, FREIHERR VON SCHOEN, W., Alfons X von Kastilien. Ein ungekrönter deutscher König, 
la perspectiva a ascender al trono imperial, un proyecto que intentaría realizar a lo largo de su reinado y que sería denominado fecho del imperio.

Desde luego, el matrimonio del año 1219 tuvo gran influencia en el desarrollo de ambos reinos, mientras que las primeras dos alianzas matrimoniales del siglo 12 no tuvieron ninguna. Resultó ser además el fundamento de la relación amistosa entre el emperador Federico II y el rey Fernando III el Santo, una amistad que se mantuvo hasta la muerte de Federico y que no fue disuelta ni el momento de la deposición y condenación del emperador como hereje. ${ }^{9}$ Por consiguiente, se impone un estudio de las fuentes para averiguar los motivos que llevaron a esta alianza matrimonial. Lo que salta a la vista es que todos los relatos ibéricos respectivos llegaron a redactarse a partir de los años 30 del siglo 13 y describen los acontecimientos con una distancia temporal significante. En el momento de la redacción la situación política en la península ibérica había cambiado para Fernando III con respecto al año 1219. Como rey se había impuesto y con el éxito con el que llevó adelante la Reconquista obtuvo la hegemonía para la corona de Castilla y León dentro de la península ibérica. ${ }^{10}$ Nuestras fuentes fueron influenciadas por este desarrollo y por consiguiente interpretaron los motivos para la alianza dinástica.

No obstante, a continuación se intentará revelar los motivos para la alianza dinástica del año 1219. En primer lugar se analizará la descripción del evento, como se nos presenta en las fuentes. En segundo lugar se relacionarán los motivos derivados de las fuentes con el contexto político en el momento de la boda.

\section{LA BODA DEL AÑO 1219 EN EL RELATO DE LAS FUENTES}

Las fuentes del reino alemán ignoran la boda que se celebró en Castilla casi por completo. Solamente tres anales contemporáneos tratan del matrimonio, principalmente para describir las relaciones dinásticas extensas de los Staufer. ${ }^{11}$ Se puede constatar que la princesa Beatriz se casó con el "rex Hispanie” o bien con el "rex Castelle sive Hyspaniae." El transcurso de la boda no forma parte del informe de los anales.

Múnich 1957, pp. 54-74, WOLF, A. "El proyecto imperial de Alfonso X”, en: Alfonso X y su época, ed. M. RODRÍGUEZ LLOPIS, Barcelona 2001, pp. 153-175 así como BALLESTEROS Y BERETTA, A., "Alfonso X de Castilla y la Corona de Alemania”, en: Revista de Archivos, Bibliotecas y Museos 34 (1916), pp. 1-23, 187219; 35 (1916), pp. 223-242.

9 Poco antes de su muerte Federico le dedicó las siguientes líneas en una carta, llena de palabras de amistad: "Pensantes amoris affectum, quem ad vos semper habuimus hactenus (...)." Historia Diplomatica Frederici Secundi sive Constitutiones, Privilegia, Mandata, Instrumenta quae supersunt istius imperatoris et filiorum ejus, ed. J.-L.-A. HOUILLARD-BREHOLLES, París 1861, vol. VI, 2, pp. 769-771, p. 769.

10 En cuanto a las expediciones militares de Fernando en Andalucía, véase GONZÁLEZ, J., "Las conquistas de Fernando III en Andalucía”, en: Hispania 6 (1946), pp. 515-631.

11 "Filia regis Philippi tradita fuit nuptui regi Hyspanie et traducta. “Annales Spirenses, ed. G. H. PERTZ, en: MGH SS 17, Hanóver 1861, pp. 80-85, p. 85. "Philippus rex habuit quattuor filias, quarum unam duxit rex Castelle sive Hyspanie, alteram rex Boemie, terciam Otto rex Romanorum, quartam (...). “ Auctarium Vindobonense, ed. G. H. PERTZ, en: MGH SS 6, Hanóver 1851, pp. 722-724, ad a. 1217, p. 723. "Habuit enim Phylippus filiam regis Constantinopolitani in coniugio (...) et ex ea IIII filias progenuit, que postea nupserunt, videlicet Ottoni postea imperatori et regi Hyspanie et regi Boemie atque duci Brabantie (...).” Annales Marbacenses qui dicuntur Cronica Hohenburgensis, ed. H. BLOCH, en: MGH SS rer. Germ [9], Hanóver/Leipzig 1907, pp. 1-103, ad a. 1211, p. 77. 
Geográficamente más cercanas, pero más de una década después, tres crónicas peninsulares relatan el transcurso de la boda. Las crónicas redactadas en su mayoría en los años 30 del siglo 13 son el Chronicon mundi del obispo Lucas de Túy ${ }^{12}$, la Chronica latina Regum Castellae anónima, pero ciertamente redactada por el obispo Juan de Osma ${ }^{13}$ así como la Historia de rebus Hispanie del Arzobispo de Toledo Rodrígo Jiménez de Rada. ${ }^{14}$

Fernando contrajo matrimonio con Beatriz el día de San Andrés, 30 de noviembre de 1219, en la iglesia de Santa María de Burgos por mediación del obispo Mauricio de Burgos, consejero leal del rey. ${ }^{15}$ Como narran las crónicas, la boda estaba enmarcada por dos acontecimientos importantes, la ceremonia en la que fue armado caballero Fernando que debía celebrarse antes de contraer matrimonio y las cortes celebradas en Burgos de cuya dimensión Juan de Osma anota: "A diebus antiquis non fuit visa talis curia in ciuitate Burgense." 16

¿Quienes fueron los participantes de la curia celebrada a continuación de la boda? Aparentemente estaban presentes todos los estamentos importantes del reino. La Chronica latina escribe que estuvieron tanto los nobles clericales como los seculares del reino castellano, asimismo la Historia de rebus Hispanie confirma la presencia durante las cortes de todos los nobles importantes. ${ }^{17}$ Aunque nuestras fuentes no lo prueban claramente, es muy probable que los acompañantes imperiales de Beatriz, enviados junto con la princesa por el emperador Federico II, hayan presenciado las diversas celebraciones que tuvieron lugar en los días de otoño tardío en Burgos. ${ }^{18} \mathrm{El}$ hecho de haber sido enmarcada la boda por acontecimientos importantes y la presencia de visitantes de alto rango que nos presentan las fuentes, dejan aparecer al rey joven en una posición elevada, ya que llevó a cabo reunir todos los nobles de su reino y propagar su esplendor hasta el Imperio por medio de los embajadores imperiales seguramente presentes.

12 Lucas Tudensis, Chronicon mundi, ed. E. FALQUE (Corpus Christianorum Continuatio Mediaevalis, vol. 74), Turnhout 2003.

13 "Chronica latina Regum Castellae", ed. L. CHARLO BREA, en: Chronica Hispana Saeculi XIII (Corpus Christianorum Continuatio Medievalis, vol. LXXIII), Turnholt 1997.

14 Rodericus Ximenius de Rada, Historia de rebus Hispanie sive Historia Gothica, ed. J. F. VALVERDE (Corpus Christianorum Continuatio Medievalis, vol. 72), Turnhout 1987.

15 "Post tercium vero diem, scilicet in festo Sancte Andree, rex dominus Fernandus duxit solempniter in uxorem predictam nobilissimam domicellam, reginam dominam Beatricem, in ecclesia Sancte Marie Burgense per manum Mauricii, Burgensis episcopi, recipiens benedictionem sacerdotatem cum eadem." Chronica latina, ed. CHARLO BREA, cap. 40, pp. 83f. Esta era la iglesia construida por Alfonso VI, predecesora de la catedral actual. El obispo Mauricio se dedicó a su construcción y fue apoyado por Fernando III. Véase Serrano, D. L., Don Mauricio. Obispo de Burgos y fundador de su catedral, Madrid 1922, pp. 57-73.

16 Chronica latina, ed. CHARLO BREA, cap. 40, p. 84.

17 "magnatum et militum et primorum ciuitatum multitudine conuocata. Asisterunt preterea regine domine Berengarie in curia illa omnes nobiliores domine tam religiose quam seculares quotquot erant in regno Castelle." Chronica latina, ed. CHARLO BREA, cap. 40, p. 84. "Et fuit ibi curia nobilissima celebrata, assistentibus tocius regni magnatibus, dominabus et fere omnibus regni militibus et primioribus ciuitatum. " Rodericus Ximenius de Rada, Historia de rebus Hispanie, ed. VALVERDE, lib. 9, cap. 10, p. 291.

18 Cuenta Rodrigo Jiménez de Rada que la princesa fue enviada a Fernando “cum apparatu nobili." Rodericus Ximenius de Rada, Historia de rebus Hispanie, ed. VALVERDE, lib. 9, cap. 10, p. 291. 


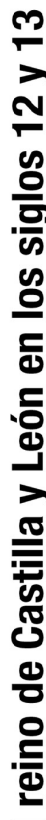

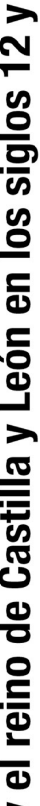

$\overrightarrow{0}$

은

을

(1)

는
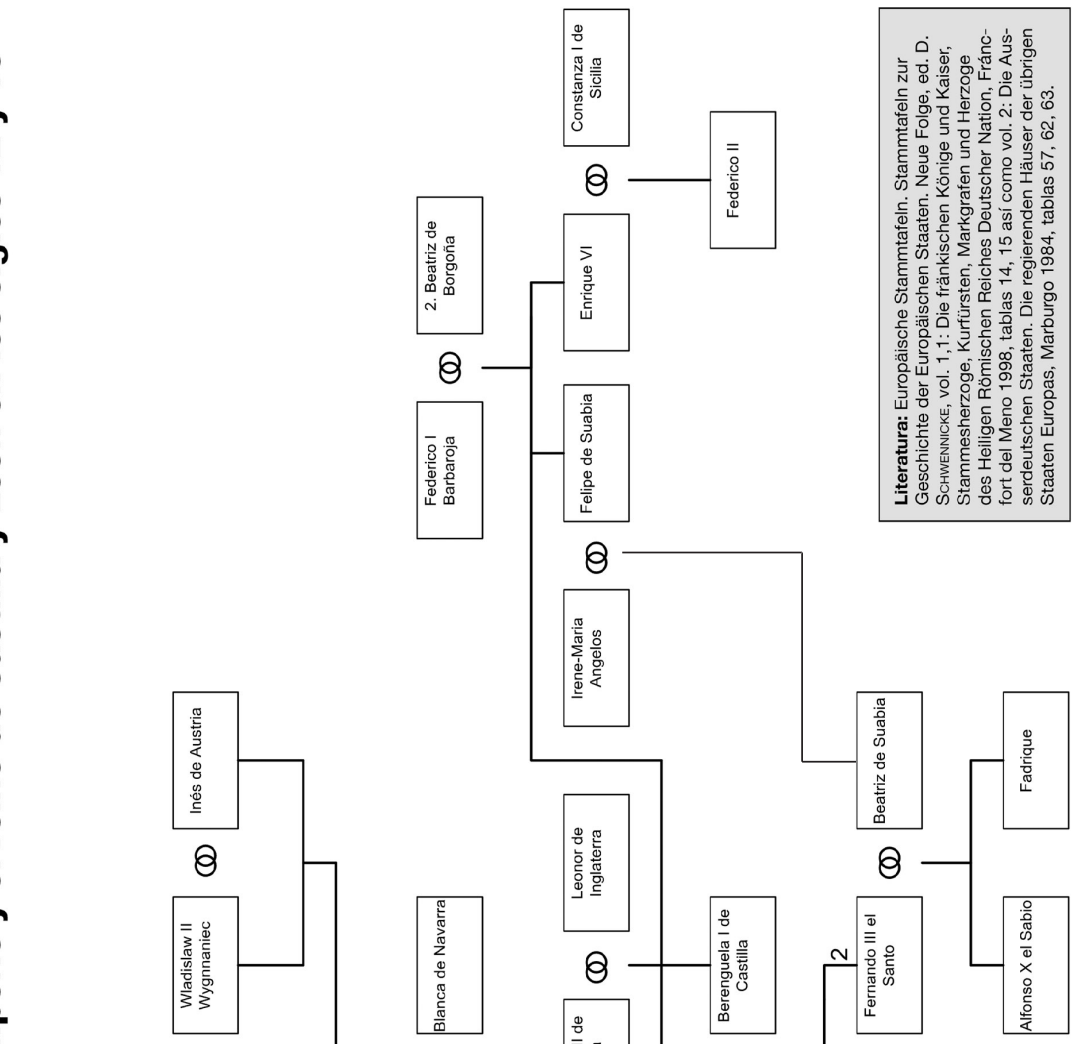

ए
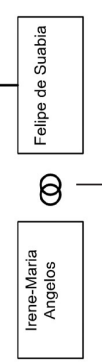

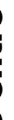

\&

를

음

음

瓷
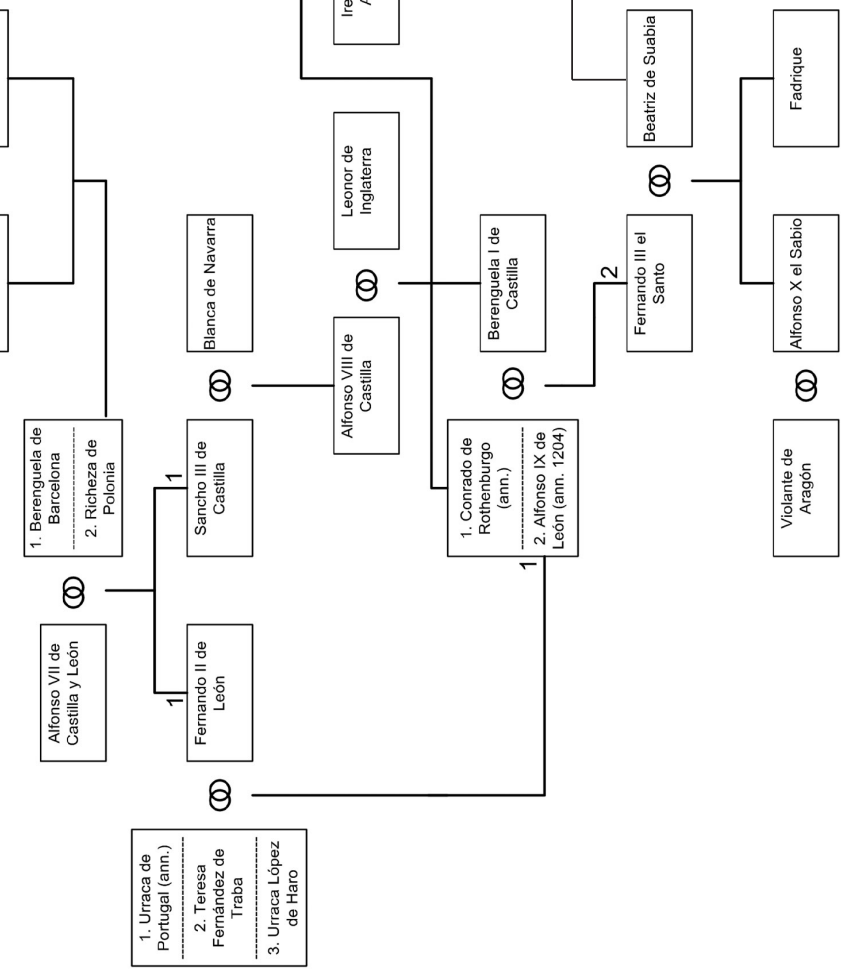

8

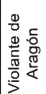


La Historia de rebus Hispanie pone de relieve de forma general, que Fernando contrajo matrimonio con Beatriz "sollempniter et legitime." ${ }^{19}$ Rodrigo remitía a la legitimidad de la boda, porque un gran número de matrimonios no canónicos habían sido anulados, lo que resultaba ser un problema constante en la península ibérica. ${ }^{20}$ No en último término, en Fernando quedaba la tacha de haber sido engendrado en un matrimonio anulado. Su madre Berenguela de Castilla se casó con Alfonso IX de León en el año 1197. En 1204, tres años después de nacer Fernando, el papa Inocencio III anuló el matrimonio por parentesco cercano y al mismo tiempo declaró que los descendientes de este matrimonio fuesen ilegítimos. ${ }^{21}$ No obstante, en el tratado de Cabreros del año 1206 Alfonso IX de León designó a su hijo Fernando como sucesor legítimo en León, lo que sería afirmado por el papa Honorio III en un diploma datado del 10 de Julio de 1218, cuando Fernando llevaba un año reinando en Castilla. ${ }^{22}$ La legitimidad también desempeñaba un papel importante en cuanto a la preparación de la boda, especialmente al describir la elección de una novia para Fernando.

\section{LAS ACTIVIDADES PREPARATIVAS DE LA ALIANZA MATRIMONIAL}

Berenguela tomó la iniciativa al elegir una novia para Fernando III. No obstante, los cronistas aducen diferentes motivos para la búsqueda. La Chronica latina alega, por ejemplo, que era "la intención de Berenguela y su mayor deseo de procurar el honor de su hijo de todos modos", por lo que inició la búsqueda. ${ }^{23}$ La expresión "honorem filii modis omnibus procurare” usada por el cronista puede referirse a dos cosas:

19 Rodericus Ximenius de Rada, Historia de rebus Hispanie, ed. VALVERDE, lib. 9, cap. 10, p. 291.

20 Por ejemplo, el papa había anulado los dos matrimonios de Alfonso IX de León por parentesco cercano. HERBERS, K., Geschichte Spaniens im Mittelalter. Vom Westgotenreich bis zum Ende des 15. Jahrhunderts, Stuttgart 2006, p. 185, VONES, L. Die Geschichte der Iberischen Halbinsel im Mittelalter (711-1480). ReicheKronen-Regionen, Sigmaringen 1993, pp. 102, 104.

21 GONZÁLEZ, J., Alfonso IX, Madrid 1944, vol. 1, pp. 116f., GONZÁLEZ JIMÉNEZ, M., Fernando III el Santo, Sevilla 2006, pp. 32-34. El parentesco cercano se debía al hecho de que Alfonso VII de Castilla y León era el bisabuelo de Berenguela y al mismo tiempo el abuelo de Alfonso IX de León. Europäische Stammtafeln. Stammtafeln zur Geschichte der Europäischen Staaten. Neue Folge, ed. D. SCHWENNICKE, vol. 2: Die Ausserdeutschen Staaten. Die regierenden Häuser der übrigen Staaten Europas, Marburgo 1984, tabla 62. Véase la bula de Inocencio III que data del 19 de junio de 1204 sobre la disolución del matrimonio en Patrologia Latina Cursus Completus, ed. J.-P. MIGNE, Paris 1844-1895, vol. 215, p. 257, col. 373-376, GONZÁLEZ JIMÉNEZ, Fernando III, pp. 43f.

22 El diploma original del tratado de Cabreros ha sido expedido el 26 de marzo de 1206: "Et demás, otorgal el rei de León, suo padre, después sue morte, todo suo regno; et fazel end fazer omenage dél.” GONZÁLEZ, J., Reinado y diplomas de Fernando III, vol. 3: Documentos (1233-1253) (Colección Estudios y Documentos), Córdoba 1986, nr. 782, pp. 365-374, p. 366. Véase el diploma comprobante de Honorio III “te ipsius [regis Legionis] successorem legitimum declarantes” en MANSILLA REOYO, D., La documentación pontificia de Honorio III (1216-1227) (Monumenta Hispaniae Vaticana, vol. 2), Roma 1965, nr. 179, pp. 141f. La aprobación del tratado por parte de Honorio se basaba en la afirmación que Alfonso IX había adoptado a Fernando, así que Fernando III legitimaría su reinado en León a través de la adopción y no por el matrimonio anulado de sus padres. Véase además MANSILLA REOLLO, D., Iglesia castellano-leonesa y curia romana en los tiempos del rey San Fernando, Madrid 1945, pp. 16f, MARTÍNEZ DÍEZ, G., Fernando III. 1217-1252, Palencia/Burgos, pp. 20-22.

23 "domina regina Berengaria, cuius intencio tota et desiderium summum erat honorem filii modis omnibus procurare (...).” Chronica latina, ed. CHARLO BREA, cap. 40, p. 82. 
1. La mujer de Fernando debía ser de su mismo rango y respecto a su honor de su misma condición.

2. Para mantener el honor de Fernando, solamente podía entrar en consideración un matrimonio legítimo, a lo que Berenguela debía prestar especial atención, como supone Serrano, por la experiencia de su propio matrimonio anulado. ${ }^{24}$ De hecho, cualquier matrimonio con un miembro de las familias reales de la península ibérica podría haber sido impugnado por la iglesia por parentesco cercano. ${ }^{25}$ Los motivos que insinúa Jiménez de Rada difieren de los de la Chronica latina. Según el cronista, Berenguela quería proteger a su hijo de lo ilícito por lo que le proporcionó una esposa, la nombrada Beatriz. ${ }^{26}$ Lucas de Túy menciona retrospectivamente los hijos que engendraron Fernando y Beatriz y anota que el matrimonio cumplió con las leyes canónicas de forma que nadie osaba impugnarlo. ${ }^{27}$

Como sabemos, la elección de una esposa adecuada recayó en Beatriz de Suabia, la prima hermana del emperador Federico II. Los cronistas tenían el afán — todos sin excepción - de subrayar su origen imperial. Mientras que Lucas de Túy solamente menciona que Beatriz procedía de "estirpe imperial" 28 , el arzobispo de Toledo y el obispo de Osma van más allá. Rodrigo nombra a su padre Felipe de Suabia y lo titula de forma correcta como electo emperador rey de Romanos y menciona a continuación a María, madre de Beatriz, que a su vez era la hija del emperador bizantino Isaac. ${ }^{29}$ Juan de Osma es aún más preciso y se refiere al doble origen imperial de Beatriz. En el árbol genealógico paternal retrocede hasta el último emperador entronizado que fue Federico I Barbaroja, al que denomina "Federici magni." Juan de Osma no se contentaba con mencionar al padre de Beatriz, ya que este no había sido entronizado como emperador. Lo que fue decisivo para el cronista era realmente el origen imperial. De la parte materna nombra igualmente la descendencia del emperador bizantino Isaac. ${ }^{30}$

Aparte de su procedencia imperial los cronistas destacan la aptitud especial de Beatriz como novia. Según Rodrigo, la princesa suaba cumplía con todos los criterios de una esposa, así que la describía con varios adjetivos positivos: distinguida, hermosa, prudente y decente. ${ }^{31}$ Conforme lo presenta Juan de Osma, este matrimonio descollaba

24 SERRANO, Don Mauricio, p. 43.

25 Ibid.

26 “mater sua, que semper uoluit eum ab illicitis custodire, procata est ei uxorem nomine Beatricem (...)." Rodericus Ximenius de Rada, Historia de rebus Hispanie, ed. VALVERDE, lib 9, cap. 10, p. 290.

27 "Omnibus etiam ecclesiis ita omnia sua iura seruauit, ut nullus esset qui auderet eas uel in aliquo molestare. “ Lucas Tudensis, Chronicon mundi, ed. FALQUE, lib. 4, cap. 93, p. 333.

28 “ex imperiale genere (...).” Lucas Tudensis, Chronicon mundi, ed. FALQUE, lib. 4, cap. 93, p. 333.

29 "procata est ei uxorem nomine Beatricem, que fuit filia regis Philipi in Romanorum imperatorem electi et Marie filie Corsaac Constantinopolitani imperatoris, que fuit optima, pulcra, sapiens et pudica; (...).” Rodericus Ximenius de Rada, Historia de rebus Hispanie, ed. VALVERDE, lib. 9, cap. 10, p. 290.

30 "Erat autem tunc in Alemania puella nobilissima, pulcra ualde, moribus et in tali etate, honesta, filia scilicet Philipi, regis Alemanie, electi in imperatorem Romanorum, filii Frederici magni, Romanorum imperatoris. Mater uero predicte puelle filia fuerat Ysaac, imperatoris Constantinopolitani (...).” Chronica latina, ed. CHARLO BREA, cap. 40, pp. 82f.

31 Véase la nota 28. 
para Berenguela a todos los demás de la cristiandad entera en "generis nobilitate." 32 Por consiguiente, la descripción de las fuentes sugiere que la unión entre Beatriz y Fernando fue realizada, ya que respetaba las reglas canónicas y porque Beatriz, por su descendencia y su aptitud especial, era una esposa adecuada para Fernando y de su misma condición.

Pero, ¿cómo fue concebida la alianza entre el Imperio y Castilla y como se inició? En su mayor parte, las fuentes no proporcionan una respuesta satisfactoria a esta cuestión. Sin embargo, los autores de la Chrónica latina y de la Historia de rebus Hispanie mencionan una embajada, que tuvo lugar inmediatamente antes de la boda y que tenía el propósito de acompañar a Beatriz desde la corte de Federico II hasta Castilla. ${ }^{33}$ Ninguna de las crónicas nos proporciona datos precisos sobre la embajada, pero debe haber tenido lugar a mediados del año 1219, dado que la boda se celebró a finales de noviembre y se debe tener en cuenta el largo viaje de los embajadores. ${ }^{34}$ Las crónicas mencionan que el obispo Mauricio de Burgos, que después iba a bendecir las armas y la espada con la que se armaría Fernando caballero, presidía la embajada. ${ }^{35}$ Los cronistas coinciden además al nombrar a Pedro Odoario, prior de la orden de los Hospitalarios, así como a Pedro Rodríguez, abad de San Pedro de Arlanza, como participantes de la embajada. ${ }^{36}$ El que el prior Juan de San Zoilo en Carrión haya formado parte de la embajada, como únicamente lo indica la Chronica latina, es demostrable mediante un diploma para su monasterio en el que Fernando le agradece su participación. ${ }^{37}$ Dado a la falta de una transmisión paralela no podemos afirmar con certeza que hayan participado en la embajada García González, antiguo maestre de la orden de Santiago, mencionado por la Chronica latina y Rodrígo,

32 "placuit predicte regine de illius matrimonio tractare que sibi uidebatur in tota christianitate precellere ceteris in genere nobilitate. " Chronica latina, ed. CHARLO BREA, cap. 40, p. 82.

33 Acerca de la embajada solemne del año 1219 a la corte del Staufer, véase OCHOA BRUN, M. A., Historia de la diplomacia española, vol. 1 (Miguel Ángel Ochoa Brun), Madrid 1991, pp. 143-146. Ochoa Brun la denomina "una de las más notables y significativas de la historia altomedieval de la diplomacia española." p. 145. Véase también MEYER, Kastilien-Staufer, pp. 76-83.

34 Serrano parte de la idea de que la embajada llegó en abril del año 1219 a Alsacia sin presentar pruebas para ello. SERRANO, Mauricio, p. 45. Para otros intentos de datación, véase FERREIRO ALEMPARTE, J., "Asentamiento y extinción de la orden Teutónica en España. La encomienda de Santa María de Castellanos de la Mota de Toro (1222-1556)", en: Boletín de la Real Academia de la Historia 168 (1971), pp. 227-274, p. 231, MEYER, Kastilien-Staufer, pp. 79f. Ochoa Brun data todas las etapas de la embajada sin indicar pruebas, así que sería especulativo tenerlas en cuenta. OCHOA BRUN, Historia de la diplomacia, vol. 1, pp. 144f.

35 OCHOA BRUN, Historia de la diplomacia, vol. 1, p. 143. Fernando mostró su agradecimiento a Mauricio por sus servicios por medio de una donación. El obispo de Burgos recibió las ciudades de Valdemoro, Quintanilla y San Mames de Favar. Véase la disposición conservada del diploma en España Sagrada, ed. H. FLOREZ, Madrid 1754-1879, vol. 26, pp. 304f.

36 "[Berenguela] missique pro ea nuncii Mauricius Burgensis episcopus, uir laudabilis et discretus, Petrus abbas sancti Petri de Aslancia, Rodericus abbas de Riuo Sicco, Petrus Odoarii prior Hospitalis ad Fredericum Romanorum regem (...)." Rodericus Ximenius de Rada, Historia de rebus Hispanie, ed. VALVERDE, lib 9, cap. 10, p. 290, “[Berenguela] misit Mauricium, Burgensem episcopum et Petrum Ouarii, priorem Hospitalis et abbatem Sancti Petri de Asilancia, et commendatarium Carrionensem, et Garsiam Gonzalui, quondam magistrum ordinis Vclensis, hoc est, milicie Sancti Iacobi. “ Chronica latina, ed. CHARLO BREA, cap. 40, p. 83.

37 El diploma del 6 de enero de 1220 declara: "necnon et intuitu gratissimi seruicii quod uos, Iohannes, prior Carrionensis et Hyspanie camerarius, eundo in Alamanniam pro karissima uxore mea regina Beatrice (...).” GONZÁLEZ, Reinado y diplomas, vol. 2, nr. 100, p. 123. Véase además IBID., vol. 1, p. 99. 
abad de la orden cisterciense indicado por la Historia de rebus Hispanie. ${ }^{38}$ Si se consideran los participantes de la embajada, puede constatarse que eran de alto rango y que entre ellos se encontraban representantes de las órdenes militares de la península ibérica.

Los cronistas nos proporcionan diferentes versiones de la llegada de los legados a la corte de Federico II. Relata el arzobispo de Toledo que en primer lugar los legados explicaron el motivo de su embajada. ${ }^{39}$ A continuación, Federico deliberó sobre el tema con sus príncipes. Finalmente, después de cuatro meses, el rey les entregó a los embajadores castellanos a su prima hermana Beatriz, que debía ser entregada a Fernando en matrimonio “cum apparatu nobili." $40 \mathrm{El}$ tenor del relato hace suponer que Federico oyó por primera vez del plan de una alianza matrimonial entre los Staufer y la corona de Castilla, ya que los legados tenían que explicar el motivo de su llegada y además esperar cuatro meses para recibir una respuesta a su propuesta. Sin embargo, el obispo de Osma se expresa todo al contrario. Antes de nombrar a los legados de la embajada escribe:

"Post alio ergo nuncios, quos domina regina premiserat in partes Alemanie pro facto isto, receptis litteris regis Alemanie, futuri imperatoris Romanorum, de mittendis nunciis solempnioribus pro adducenda domicella, misit (...).” ${ }_{41}$

Según Juan de Osma, la reina Berenguela ya había mandado anteriormente una embajada a Alemania. Esta había cumplido la misma misión, posiblemente de concertar una alianza dinástica. Podemos deducir del relato que en el orden cronológico Berenguela reaccionó de nuevo con una embajada "receptis litteris regis Alemanie”, es decir, después de haber recibido cartas del rey de Alemania. Federico II le había pedido "de mittendis nunciis solempnioribus pro adducenda domicella." Con la participación de personajes de alto rango en la embajada, Berenguela y Fernando ya habrían satisfecho el deseo de Federico de enviar una embajada solemne para acompañar a Beatriz a Castilla. Si se sigue este relato, la alianza dinástica y la elección de la novia se habrían concertado mucho antes de la embajada del año 1219. La existencia de dos versiones diferentes sobre el desarrollo de la embajada ha llevado a interpretaciones contradictorias. Mientras que Ochoa Brun, González y Socarras se basan en la veracidad de las afirmaciones de la Chronica latina sobre una embajada anterior datándola en el año 1218, Meyer la descarta por completo. ${ }^{42}$ El grupo confirmador no indica pruebas para su afirmación sino que sigue en este asunto

38 No obstante, Ochoa Brun supone que participaron en la embajada. Según él, las dos crónicas son las más confiables de su época y se complementan mutuamente. OCHOA BRUN, Historia de la diplomacia, p. 143.

39 "Cumque legationis causam, ut iniunctum fuerat, explicassent, predictus rex et sui principes responsionem aliquandiu suspenderunt et fere per menses IIIIor predicti nuncii expectarunt. Tandem rex Fredericus in imperatorem electus consobrinam suam Beatricem, domicellam nobilem, pulchram, compositam et prudentem, regi Fernando per predictos nuncios cum apparatu nobili destinauit." Rodericus Ximenius de Rada, Historia de rebus Hispanie, ed. VALVERDE, lib 9, cap. 10, pp. $290 \mathrm{f}$.

40 Véase la nota 38.

41 Chronica latina, ed. CHARLO BREA, cap. 40, p. 83.

42 OCHOA BRUN, Historia de la diplomacia, vol. 1, p. 144, GONZÁLEZ, Reinado y diplomas, vol. 1, p. 97 así como SOCARRAS, C. J., Alfonso X of Castile: A study of imperialistic frustration, Barcelona 1975, pp. 103f., MEYER, Kastilien-Staufer, p. 78. 
al relato más detallado de la Chronica latina. Meyer remite para su interpretación contraria a un pasaje de la Primera Crónica General, que se empezó a componer una generación después bajo Alfonso X. ${ }^{43}$ Esta sostiene la versión de la Historia de rebus Hispanie, siendo extraída de esta y traducida casi literalmente a la lengua vernácula. ${ }^{44}$ De este modo, la interpretación de un relato derivado de la Primera Crónica General no puede proporcionar pistas para afirmar que Federico II necesitara cuatro meses para reflexionar sobre este proyecto, con el que supuestamente se le había confrontado por primera vez. No es posible obtener una aclaración basada en las fuentes existentes de la discrepancia entre las crónicas. Pero hay que tener en cuenta que una estancia de cuatro meses no era algo fuera de lo común para una embajada solemne y tampoco es obligatorio de interpretarla como tiempo que se necesitaba para poner en balanza un asunto nuevo. El tiempo de consulta podría aludir a negociaciones preliminares de las que no estamos informados y en las que se concluyó un contrato cuyo cumplimiento se examinaba durante la estancia de los legados. Un ejemplo sería la boda de Berenguela con Conrado de Rothenburgo en el año 1188, para la que previamente se había concluido un contrato matrimonial durante varias consultas. ${ }^{45}$ Diago Hernando opina que el tiempo de espera se derivaba del hecho, de que Beatriz aún no se encontraba en la corte real. ${ }^{46}$ Argumenta de acuerdo con Winkler quien opina que Beatriz había sido entregada a Federico II el 24 de junio de 1219 por el hermano de su antiguo rival Otón IV, bajo cuya custodia había estado la princesa hasta su muerte. ${ }^{47}$ De hecho, no podemos comprobar este hecho por medio de nuestras fuentes, pero parece plausible. En cambio, toda reconstrucción del transcurso de la embajada es especulación, porque ni las fuentes ibéricas ni las alemanas nos proporcionan informaciones suficientes. ${ }^{48}$ Asimismo, el que las fuentes alemanas no mencionen una embajada

43 La obra siguió completándose bajo Sancho IV y sirvió de base para crónias posteriores. Primera Crónica General, ed. MENÉNDEZ PIDAL (Nueva biblioteca de autores españoles, vol. 5), Madrid 1906, [Reimpresión: Madrid 1977].

44 "et fueron a don Fredric rey de los romanos, en cuya guarda estaua entonçes la donzella donna Beatriç en Alemanna, et alli fueron estos mandaderos por ella; et rrecibiolos esse rey muy onrradamientre. Et pues que se razonaron et departieron en muchas buenas razones daca de la tierra, et al cabo mostraron la razon, assi como les fue mandado, por que eran alli venidos. El sobredicho rey et sus prinçipes ouieron su fabla sobrello, et detouieronles la respuesta por algunos dias, et los mandaderos esperaronla; et los dias de la respuesta fueron bien quatro meses, de como cuenta la estoria. " Primera Crónica General, ed. MENÉNDEZ PIDAL, cap. 1034, p. 718.

45 Acerca del pactum matrimoniale de Seligenstadt, véase RASSOW, P., Der Prinzgemahl. Ein pactum matrimoniale aus dem Jahre 1188 (Quellen und Studien zur Verfassungsgeschichte des Deutschen Reiches in Mittelalter und Neuzeit, vol. 8, 1), Weimar 1950.

46 DIAGO HERNANDO, M., "La monarquía castellana y los Staufer. Contactos políticos y diplomáticos en los siglos XII y XIII”, en: Espacio, Tiempo y Forma, Serie III, 8 (1995), pp. 51-83, vid. pp. 64-66.

47 WINKELMANN, Kaiser Friedrich II., Leipzig 1889 (reimpresión: Darmstadt 1963), vol. 1, p. 23, nota 1. Véase además Regesta Imperii V, 1, Die Regesten des Kaiserreiches unter Philipp, Otto IV., Friedrich II., Heinrich (VII.), Conrad IV., Heinrich Raspe, Wilhelm und Richard 1198-1272, ed. J. F. BÖHMER/J. FICKER/E. WINKELMANN, 4 voll., Innsbruck 1881 (Reimpresión: Hildesheim 1971), nr. 1025a, p. 238.

48 Ochoa Brun supone que los legados seguían a la corte de Federico II durante su estancia en el reino. Por esta razón nombra los diferentes lugares de residencia del rey desde mayo hasta septiembre de 1219 pero no puede probar la presencia de los legados. OCHOA BRUN, Historia de la diplomacia, vol. 1, p. 144. Meyer supone que hubo al menos dos encuentros entre los legados y Federico e intenta reconstruir varios lugares de encuentro de los embajadores con la corte a base del relato de las fuentes, pero no llega a una conclusión. MEYER, Kastilien-Staufer, pp. 79f. Acerca de los lugares de residencia de la corte de Federico II en el año 1219 , véase RI V, 1, nr. 970-1080, pp. 229-247 así como V, 4, nr. 157-173 pp. 25-27. 
previa no demuestra que no la hubo. Como pudimos ver, ante todo, su intención era de exponer las alianzas dinásticas extensas de los Staufer, por lo que se conformaban con mencionar la boda con el "rex Hispanie" o bien con el "rex Castelle sive Hyspaniae." 49 Por consiguiente, ciertamente no habrían registrado una embajada castellana preliminar. Además, el que no se haya conservado la carta correspondiente de Federico II a la que alude la Chronica latina, no quiere decir que el relato sea falso. Aún hoy en día las fuentes transmitidas se complementan por medio de descubrimientos inesperados. Así lo demuestra una carta de Federico II dirigida a Fernando III que en el año 2004 se encontró dentro del código 400 de Innsbruck y que hasta ahora era desconocida. ${ }^{50}$

Como demuestra el proyecto matrimonial del año 1188, las embajadas de sondeo previas y contratos matrimoniales eran usuales en las alianzas matrimoniales entre la corona de Castilla y los Staufer. Un tal contrato no ha sido transmitido para el matrimonio de Fernando III con Beatriz de Suabia, no obstante puede haber existido. ${ }^{51}$ También lo indica la confirmación posterior de la dote de Beatriz por Honorio III que fue redactada en agosto del año $1222 .{ }^{52}$ La dote puede haber formado parte de un contrato matrimonial. Asimismo, la embajada solemne que Federico II pidió según la Chronica latina seguramente correspondía con el procedimiento habitual ante una alianza matrimonial e indica por otra parte que el relato de Juan de Osma es convincente en este punto. Por lo tanto, es de suponer que el contacto entre Federico II y Fernando III respecto a una alianza matrimonial se había establecido antes de la embajada del año 1219, ya que un tal matrimonio no debe haberse concertado de improviso durante una sola embajada.

\section{LOS MOTIVOS DE LA ALIANZA MATRIMONIAL}

Las fuentes ibéricas analizadas presentan al rey Fernando en una posición poderosa a la hora de contraer matrimonio en el año 1219. Por lo tanto, no es de sorprender que como motivo para el matrimonio sólo indiquen que Berenguela quería proteger a su hijo de lo ilícito o bien procurar su honor. La ambición de Berenguela de buscar una esposa adecuada para su hijo no deja llegar únicamente a la conclusión de que Fernando, para cumplir las reglas canónicas de un matrimonio legítimo, solamente quería casarse con una persona con un grado de parentesco suficientemente lejano. La elección de Berenguela recayó en Beatriz de cuyo doble origen imperial nos informan claramente los cronistas. Si

49 Véase la nota 10.

50 RIEDMANN, J., "Unbekannte Schreiben Kaiser Friedrichs II. und Konrads IV. in einer Handschrift der Universitätsbibliothek Innsbruck. Forschungsbericht und vorläufige Analyse", en: Deutsches Archiv für die Erforschung des Mittelalters 62 (2006), pp. 135-200.

51 Según Meyer, la elaboración de un contrato matrimonial para el matrimonio de Fernando III y Beatriz no es forzoso ya que no estaban en juego derechos de sucesión al trono. MEYER, Kastilien-Staufer, p. 78. Sin embargo, debe haber existido una regulación de la dote de Beatriz. Véase FÖßEL, A., Die Königin im mittelalterlichen Reich. Herrschaftsausübung, Herrschaftsrechte, Handlungsspielräume (Mittelalter-Forschungen, vol. 4), Stuttgart 2000, pp. 67-80.

52 Véase el diploma de confirmación en La documentación pontificia de Honorio III (1216-1227), ed. D. MANSILlA REOYO (Monumenta Hispaniae Vaticana, vol. 2), Roma 1965, nr. 411, p. 304. Se trataba de dominios que ya se habían confirmado para Berenguela en el contrato de matrimonio de Seligenstadt del año 1188 . 
seguimos al relato de la Chronica latina, esta alianza era superior a todas las demás, que posiblemente se habían tomado en consideración. En la retrospectiva, los cronistas evocan la impresión de que Beatriz ante todo entraba en consideración como esposa, porque sólo una princesa con origen imperial era de igual condición que el rey Fernando. El rango del rey de Castilla - y desde el año 1230 también de León - y la posición hegemónica de sus reinos como subsistía en el momento de redactarse las crónicas es proyectado en los eventos del año 1219. Pero, ¿cuál fue la realidad política del año 1219 y qué conclusiones pueden derivarse en cuanto a los motivos para la boda?

Fernando llevaba únicamente dos años sobre el trono de Castilla en el momento de casarse. Con sólo 16 años de edad había sido entronizado cuando su tío regente Enrique I, que era tres años menor que Fernando, había muerto en un accidente trágico y Berenguela había renunciado al trono a favor de su hijo Fernando. ${ }^{53}$ Sin duda alguna, la sola renuncia de Berenguela no hizo de Fernando un rey. Con la ayuda de sus consejeros fieles logró Berenguela abrirle el paso al trono a pesar de la oposición de su antiguo marido Alfonso IX de León, que también quería acceder al trono de Castilla, y a pesar de la oposición de un grupo de magnates. ${ }^{54}$

A raíz de la oposición paternal y de los magnates presidida por Álvaro Núñez de Lara, quien como regente de Enrique I había sufrido la pérdida del poder después de la muerte del rey, la toma del poder de Fernando III resultaba ser especialmente difícil. ${ }^{55}$ Tras acciones militares contra Castilla de parte de León el camino hacia la paz se allanó

53 Enrique I murió a razón de una herida en el cráneo que había contraído al jugar con jóvenes de su misma edad. Chronica latina, ed. CHARLO BREA, cap. 32, p. 76, Rodericus Ximenius de Rada, Historia de rebus Hispanie, ed. VALVERDE, lib. 9, cap. 4, pp. 284f., Lucas Tudensis, Chronicon mundi, ed. FALQUE, lib. 4, cap. 92, p. 332. En cuanto a la sucesión de Berenguela, véase MARTÍNEZ DÍEZ, Fernando III, pp. 31, 34. Respecto a la sucesión femenina, véase RASSOW, Prinzgemahl, pp. 98-111.

54 Al morir Enrique I, Berenguela dejó traer a Castilla a su hijo que se encontraba en la corte de Alfonso IX para entronizarle como rey. Alfonso IX no debía saber nada de la muerte del rey de Castilla y de la artimaña de Berenguela. "Audita morte fratris (...) regina Berengaria misit nuncios suos, (...) ad regem Legionis, qui tunc erat apud Taurum, ut filium suum maiorem natu, scilicet dominum Fernandum, qui tunc erat cum patre (...). Predicti uero nobiles, accedentes ad regem Legionis, utilem simulationem inuenerunt, per quam uoti compotes effecti sunt, et puerum predictum cum multa celeritate ad matrem (....) adduxerunt." Chronica latina, ed. CHARLO BREA, cap. 33, pp. 76f. "regina sapiens misit (...) pro filio suo Fernando, qui apud Taurum cum patre tunc temporis morabatur." Rodericus Ximenius de Rada, Historia de rebus Hispanie, ed. VALVERDE, lib. 9, cap. 4, p. 285. Entre los colaboradores de Berenguela, que fueron a Toro donde se encontraba Alfonso IX, estaban Don Lope Díaz de Haro y Gonzalo Ruiz Girón. OCHOA BRUN, Historia de la diplomacia española, p. 142. Tras Berenguela se formaba un grupo de magnates entre los que estaban Lope Díaz de Haro, Rodrigo Díaz de Cameros así como más tarde Gonzalo Rodríguez, sus hermanos y Alfonso Téllez. GARCÍA PELEGRÍN, J., Studien zum Hochadel der Königreiche León und Kastilien im Hochmittelalter (Spanische Forschungen der Görres-Gesellschaft, seg. col., vol. 26), Münster 1991, pp. 141-143 así como GONZÁLEZ, Reinado y diplomas, vol. 1, pp. $69 \mathrm{f}$.

55 Álvaro Núñez de Lara se había apoderado de la regencia de Enrique I y a su vez quería asumir la regencia de Fernando. GONZÁLEZ JIMÉNEZ, Fernando III, pp. 38f. La regencia de Álvaro había causado el ascenso de su familia hacia las primeras familias de Castilla de forma que podía gobernar beneficiándose a sí mismo. MARTÍNEZ DÍEZ, Fernando III, p. 24. Además, Álvaro y su hermano Gonzalo usaban el título de comes. Con respecto a la regencia de Berenguela y de Álvaro, véase DE LA CRUZ, F. V., Berenguela la Grande. Enrique I el Chico (1179-1246), Gijón 2006, pp. 109-152. 
cuando Álvaro Núñez de Lara fue tomado preso el 19 de septiembre de $1217 .{ }^{56}$ Aunque las negociaciones de paz entre Alfonso IX y Fernando III culminaron en el tratado de Toro del 26 de agosto de 1218 y en el reconocimiento de Fernando como rey de Castilla, su gobierno no era indiscutido. ${ }^{57}$ Hasta el año 1224, en el que concluía la tregua con el reino musulmán de los almohades, Fernando tenía que reprimir en su reino diversas sublevaciones de los magnates y apaciguar a Castilla. ${ }^{58}$ Para tal fin comenzaba Fernando ya en el año 1218 a visitar las ciudades más importantes de su reino. Después de su boda en noviembre de 1219 empezó a visitarlas junto con su esposa Beatriz, que aparentemente cumplía una función legitimadora. ${ }^{59}$

La situación política-real de los primeros años del reinado de Fernando demuestra que deben ponerse en tela de juicio las afirmaciones de las fuentes que aluden a una posición poderosa de Fernando. El matrimonio con Beatriz significaba más bien un ascenso para el rey castellano. Este ascenso forma parte de una estrategia de legitimación ya que Beatriz no era solamente una esposa adecuada por ser de igual condición que Fernando, sino que revalorizó la posición del rey de Castilla. Fernando se esforzaba por incrementar su autoridad como rey hasta fuera de la península ibérica para lo que a su vez podían haber servido los suntuosos actos solemnes alrededor de su boda. Los cronistas redactaron sus relatos posteriormente durante la época exitosa del reinado de Fernando y sin duda estaban contentos con su reinado. Por consiguiente les interesó presentarlo de forma positiva y poderosa, ya que no en último término le agradecían sus puestos elevados al rey. Evidentemente, como móvil para la alianza matrimonial con una Staufer se pueden suponer motivos tácticos.

Pero también al emperador Federico II le convenía la alianza con la corona de Castilla. Por lo visto, después de haberse impuesto al emperador Otón IV como rey de Romanos con la ayuda del rey francés Felipe II Augusto, ${ }^{60}$ ampliaba sus relaciones con otras casas reales. La alianza con el reino de Castilla que destacó en el transcurso de la Reconquista tiene que haber sido bastante atractiva para Federico II, ya que estaba preparando su coronación como emperador por lo que podía sacar ventaja de las buenas relaciones que

56 Álvaro Núñez de Lara murió en el verano del año 1218. GARCÍA PELEGRÍN, Studien zum Hochadel, p. 144.

57 Véase el texto del tratado en GONZÁLEZ, Alfonso IX, vol. 2, nr. 366, p. 479. En cuanto a las negociaciones de paz y al tratado de Toro, véase MARTÍNEZ DÍEZ, Fernando III, pp. 51-53.

58 La tregua fue negociada por Alfonso VIII de Castilla y debía mantenerse entre los años 1214 y 1224. GONZÁLEZ, J., El Reino de Castilla en la época de Alfonso VIII, vol. 1: Estudio (Consejo Superior de Investigaciones Científicas. Escuela de Estudios Medievales. Textos, vol. 26), Madrid 1960, p. 1072, MARTÍNEZ DÍEZ, Fernando III, pp. 62-65. Acerca de las sublevaciones de los magnates en el reino de Castilla, véase IBID., Fernando III, pp. 65-72.

59 MARTÍNEZ DÍEZ, Fernando III, pp. 59f.

60 El desenlace de la batalla de Bouvines del año 1214 había consolidado la legitimidad de Federico como rey de Romanos. Acerca de la batalla de Bouvines, véase SCHNITH, K., art. "Schlacht von Bouvines", en: Lexikon des Mittelalters, vol. 2, col. 522-523 así como DUBY, G., Der Sonntag von Bouvines, Berlín 1988. Acerca del efecto de la batalla en la legitimidad de Federico, véase STÜRNER, W., Friedrich II., vol. 1: Die Königsherrschaft in Sizilien und Deutschland, Darmstadt 2003, pp. 163-168. 
mantenía el rey castellano con el papado. ${ }^{61}$ La reorganización eclesiástica de los territorios reconquistados de la península ibérica había causado el acercamiento de los reinos ibéricos con la sede apostólica. ${ }^{62}$ Efectivamente podemos suponer que también Federico II tenía motivos tácticos al realizar la alianza dinástica con el reino de Castilla.

De esta alianza dinástica entre los Staufer y la corona de Castilla, que en primer plano se había proyectado con fines tácticos de corto plazo, surgió una amistad entre el emperador Federico II y el rey Fernando III el Santo. ${ }^{63}$ Por medio de la cooperación mutua en asuntos militares así como por el afán especial de Beatriz de mantener las relaciones con el emperador, se intensificó la alianza. Se dio además una perspectiva europea a los hijos del rey Fernando III, de los cuales sobre todo Alfonso y Fadrique tuvieron la oportunidad de beneficiarse al entrar en relaciones directas con el emperador Federico II.

61 Federico fue coronado emperador el 22 de noviembre del año 1220 por Honório III después de haberle asegurado de mantener separados el reino alemán del siciliano. Véase STÜRNER, Friedrich II., vol. 1, pp. 246253 así como HOUBEN, H., Kaiser Friedrich II. 1194-1250: Herrscher, Mensch, Mythos (Kohlhammer Urban Taschenbücher, vol. 618), Stuttgart 2008, pp. 36-38. Con respecto a las buenas relaciones de Fernando con la curia romana, véase MANSILLA REOLLO, D., Iglesia castellano-leonesa y curia romana en los tiempos del rey San Fernando, Madrid 1945, pp. 9-29, DÍAZ IBÁÑEZ, J., "Fernando III, Inocencio IV y los fundamentos de la soberanía regia sobre la iglesia en la corona de Castilla", en: Fernando III y su tiempo (1201-1252). VIII Congreso de Estudios Medievales (León 1-4 de octubre de 2001), Ávila 2003, pp. 325-341.

62 HERBERS, Geschichte Spaniens, p. 157.

63 Véase GIUNTA, F., "Federico II e Ferdinando III di Castiglia", en: Papers of the British School at Rome 24 (1956), pp. 137-141, FERREIRO ALEMPARTE, J., "Acercamiento mutuo entre España y Alemania con Fernando III y Alfonso X el común”, en: España y Europa, un pasado jurídico común, ed. A. PÉREZ MARTÍN, Murcia 1986, pp. 179-222. 